\title{
SOIL-STRUCTURE INTERACTION ANALYSES OF PILE SUPPORTED BUILDING FRAME
}

\author{
H.S. Chore* and R.K. Ingle \\ Department of Applied Mechanics, Visvesvaraya National Institute of Technology, \\ Nagpur- 440 010, India
}

Received 07 March 2007

\begin{abstract}
The effect of the soil-structure interaction on the simple single storeyed and two bayed space frame resting on pile group of two piles with flexible cap is examined in this paper by resorting to more rational approach and realistic assumptions. Initially, 3-D FEA is carried out independently for the frame on the premised of fixed column bases. Later, pile foundation is worked out separately. The stiffness so obtained for foundation is used in the interactive analysis of frame to quantify the effect of soil- structure interaction on the response of the superstructure. For modeling the foundation system two approaches of finite element analysis are used. In the first approach complete three dimensional finite element analysis is resorted to wherein pile, pile cap along with the soil are discretized into 20 noded isoparametric continnum elements and interface between pile and soil is idealized as 16 noded isoparametric interface elements. In the second approach simplified finite element analysis procedure is used wherein beam element, plate element and spring elements are used to model pile, pile cap and soil respectively. The salient feature of the investigation is that the interaction between pile cap and soil underlying it is considered. In the parametric study presented here, effect of pile spacing and pile configuration is evaluated on the response of superstructure in the form top displacement in frame and bending moment at top as well as bottom of the superstructure columns. Results obtained by either analysis are compared.
\end{abstract}

Keywords: Pile Group, Spacing, Configuration, Top Displacement of Frame, B.M. in Columns

\section{INTRODUCTION}

Superstructure frames are normally analyzed considering their bases to be either completely rigid or hinged. Notwithstanding, the foundation resting on deformable soil also undergoes deformation depending on the relative rigidities of the foundation, the superstructure and soil. Interactive analysis is, therefore, necessary for the correct assessment of the response of the superstructure. Such interactive analyses have been reported in many studies [1 - 4] in the decade of sixties and seventies or even in few studies [5 - 8] in the recent past.

The majority of the above studies deal either with the interaction of frames with isolated footings, or with raft foundation or with interaction of rafts with pile foundations. In the latter category, the analysis of three-dimensional pile foundation in which response of the foundation head is considered, itself requires the major efforts. Depending upon the load applied at the foundation head, various approaches are available for analysis of the pile group. Even though

\footnotetext{
* Corresponding author e-mail: hschore@ rediffmail.com
} 
pile group may be subjected to axial loads, in most of the cases combination of the axial and lateral load act on the pile foundation, which further complicates the analysis. The conventional approaches available for the analysis of axially loaded pile foundation are Elastic Continuum Method [9] and Load Transfer Method [10] while the approaches available for analyzing laterally loaded pile foundation include Elastic Approach [11] and Modulus of Subgrade Reaction Approach [12] With the advent of computers in early seventies, more versatile finite element method [13] has become popular. In one of the studies [14] simplified finite element analysis was suggested for the soil-structure interaction problem and also pointed out the consideration of the interaction of the pile cap and underlying soil. On the similar lines, significance of this interaction aspect in the analysis of pile group was demonstrated in another study [15]. Although extensive work is reported on the analysis of superstructure frames resting on either isolated footings or on raft foundation to quantify the effect of soil- structure interaction on the response of the superstructure, much less work is found on the analysis of framed structure resting on the pile foundation. In one such study [16] space frame resting on pile foundation was evaluated in order to quantify the effect of soil-structure interaction by resorting to very simplified assumptions.

\section{SIGNIFICANCE OF PRESENT WORK}

The investigation reported by Buragohain et al [16] was attempted by stiffness matrix method. Pile cap was considered rigid and stiffness of the pile cap was not considered. Stiffness matrix for the entire pile group was derived the by principle of superposition using rigid body transformation. Foundation stiffness matrix was then combined with the superstructure matrix for attempting the interactive analysis. However, for the purpose of more rational and realistic analysis flexible pile cap along with its stiffness is considered and stiffness matrix for the substructure is derived at a time by considering the effect of all the piles in a group in the present investigation. The salient feature of the present investigation is that it takes into account the interaction between the pile cap and the soil underlying and surrounding it, the neglected parameter in the analysis of pile group.

\section{IDEALIZATIONS MADE IN THE PROPOSED ANALYSIS}

Three-dimensional (3-D) finite element analysis is used for the analysis of the building frame on the premise of fixed support. The elements of the superstructure (Beam, column and slab) are discretized into a number of 20 noded iso-parametric continuum elements. Analysis of pile foundation is attempted by two finite element procedures- firstly, by complete three dimensional finite element analysis and secondly, by using simplified finite element models.

In the former approach, pile and pile cap along with the soil is discretized into 20 noded isoparametric continuum elements while interface between pile and soil is idealized as 16 noded isoparametric interface elements. In the latter approach more simplified finite element models as suggested by Desai et al [14] are used here using well-known concepts in the theory of finite elements. Beam element, plate element and spring element are used to simulate pile, pile cap and foundation soil. In this way, a complete 3-D system of the substructure is replaced by 1-D idealization of piles, 2-D idealization of pile cap; and equivalent springs for foundation soil. The memory requirement is nearly one tenth of actual 3-D formulation. In this manner, more complex problems can be handled with significant accuracy.

\subsection{Method of Analysis}

Stiffness matrices for pile, soil and pile cap are assembled in global stiffness matrix. From assembled global stiffness matrix and known load vector, overall equilibrium equations are 
formulated. The resulting equations are solved for unknown nodal displacements by gauss elimination. After computation of nodal displacements, stiffness matrix of each element is recalled to get the internal forces such as axial force, shear force and bending moment, within the element.

On premise of the above-mentioned idealizations, a software program was developed and after having validated it on the primary structures such as cantilever beam and portal frame, the same was implemented for the analysis of specific frame considered in the problem.

\section{PROBLEM DESCRIPTION}

A 3-D single storeyed building frame resting on pile foundation, as shown in the Fig. 1, has been considered for the study. The frame, $3 \mathrm{~m}$ high is $10 \mathrm{~m} \times 10 \mathrm{~m}$ in plan with each bay being, $5 \mathrm{~m} \times 5 \mathrm{~m}$. The slab, $200 \mathrm{~mm}$ thick, is provided at top as well as at the floor level. Slab at top is supported over $300 \mathrm{~mm}$ wide and $400 \mathrm{~mm}$ deep beam. The beams are resting on columns of size $300 \mathrm{~mm} \times 300 \mathrm{~mm}$. Mathematical model of the building frame considered in the study discretized into 20 noded isoparametric continuum elements is shown in Fig. 2. Two configurations of the Pile Foundation considered in the present study include group of two piles with series and parallel arrangement of piles therein (Fig. 3). Piles are embedded in soft marine clay. All the piles in a group are connected by flexible pile cap. M- 20 grade of concrete is assumed for superstructure elements and M-40 grade of concrete, that for substructure elements.

\section{Material properties for pile, soil and interface:}

- Pile: Modulus of Elasticity $\left(\mathrm{E}_{\mathrm{c}}\right)=0.3605 \times 10^{8} \mathrm{kPa}$, Length $(\mathrm{L})=3 \mathrm{~m}$, Size $(\mathrm{D})=300 \mathrm{~mm}$,

- Cap: Modulus of Elasticity $\left(\mathrm{E}_{\mathrm{c}}\right)=0.3605 \times 10^{8} \mathrm{kPa}$, Poisson's ratio $\left(\mu_{\mathrm{c}}\right)=0.15,500 \mathrm{~mm}$ thick.

- Soil: Modulus of Elasticity $\left(\mathrm{E}_{\mathrm{s}}\right)=4267 \mathrm{kPa}$, Poisson's ratio $\left(\mu_{\mathrm{s}}\right)=0.45, \mathrm{~K}_{\mathrm{s}}=6667 \mathrm{kN} / \mathrm{m}^{3}$.

- Interface: Shear stiffness $\left(\mathrm{k}_{\mathrm{s}}\right)=1000 \mathrm{kN} / \mathrm{m}$, Normal stiffness $\left(\mathrm{k}_{\mathrm{n}}\right)=1.0 \mathrm{E} 06 \mathrm{kN} / \mathrm{m}^{3}$.

Initially, analysis for pile foundation was worked out separately for unit lateral load and unit vertical load to get equivalent spring stiffness for pile foundation. These springs stiffness was then used in the analysis of frame.

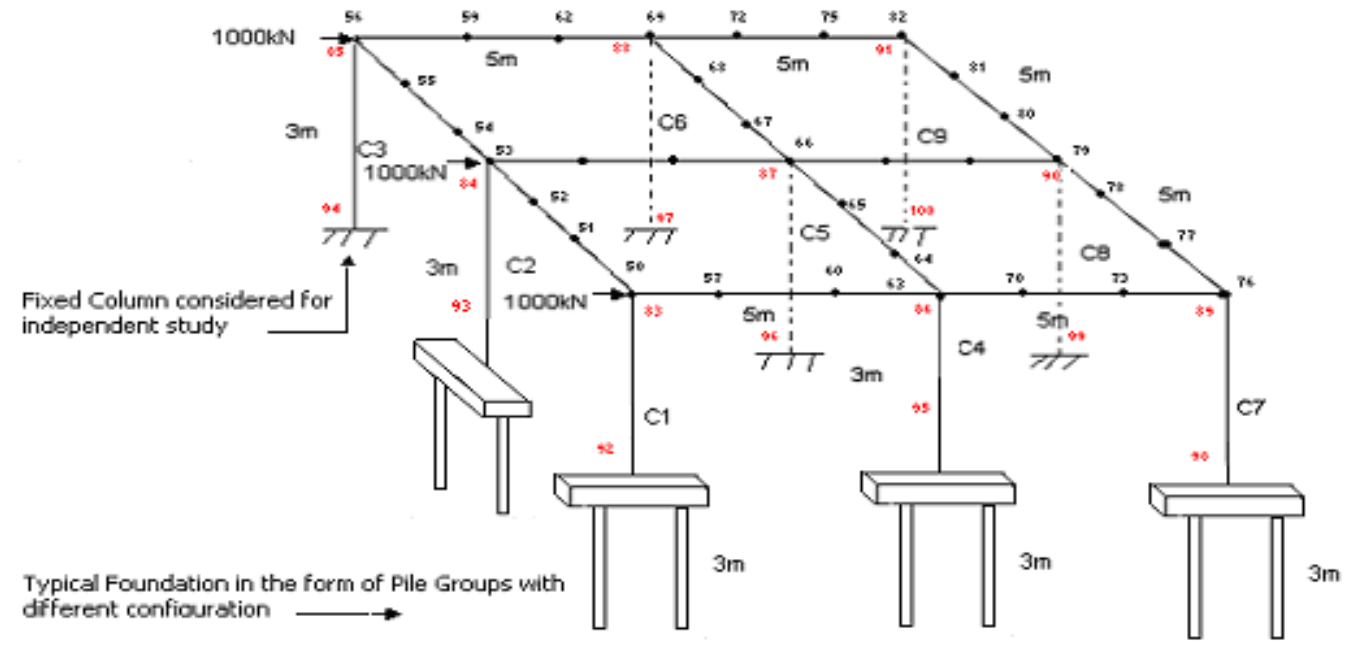


Fig. 1: Typical 3-D building frame considered in the study.

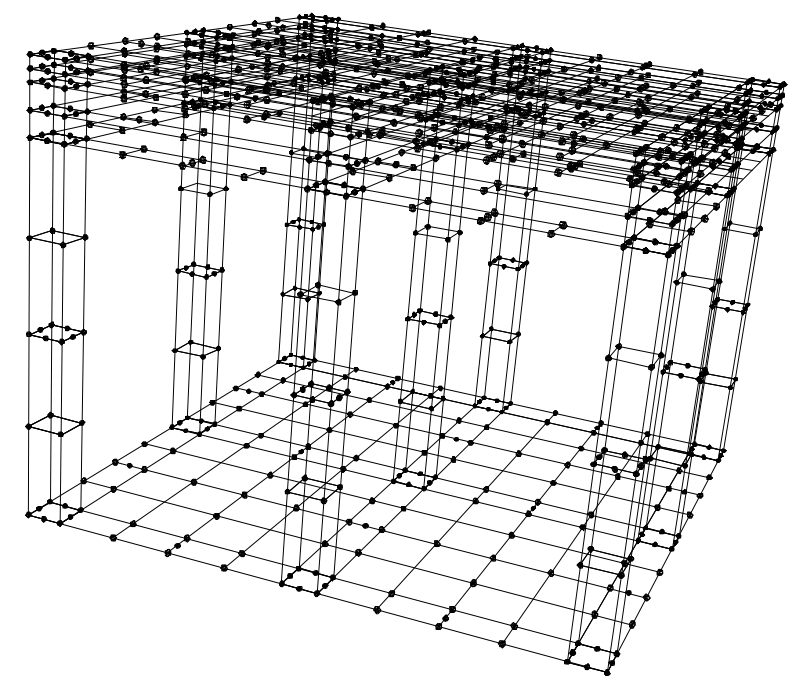

Fig. 2: Mathematical model of the building frame.

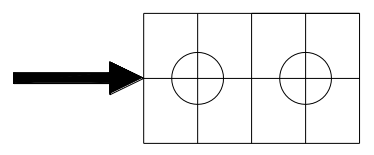

SERIES CONFIGURATION

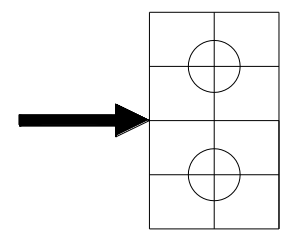

PARALLEL ARRANGEMENT

TWO- PILE GROUP

Fig. 3: Different configurations of the pile group.

\section{RESULTS AND DISCUSSION}

In the parametric study presented here, response of the superstructure in the form of the parameters such as top displacement in frame and bending moment at top as well as bottom of the superstructure columns in view of the fixed base and pile foundation are considered for the purpose of comparison. Effect of the pile spacing and configuration of the pile group is evaluated on the response of the superstructure. Top displacement of the frame is presented in Table 1. Few results pertaining to the variation in B.M. at top and bottom of the typical columns are presented in Figs. 4 and 5. 
Table 1: Displacements at Top of Frame (in $\mathrm{mm}$ ).

\begin{tabular}{lcccccc}
\hline $\begin{array}{c}\text { Condition of } \\
\text { Support }\end{array}$ & \multicolumn{2}{c}{ 3-D F. E. Analysis } & \multicolumn{2}{c}{$\begin{array}{c}\text { Simplified F.E. Analysis } \\
\text { (With interaction) }\end{array}$} & $\begin{array}{c}\text { Simplified F.E. Analysis } \\
\text { (Without interaction) }\end{array}$ \\
\cline { 2 - 7 } & G2PS & G2PP & G2PS & G2PP & G2PS & G2PP \\
\hline Fixed & & & & 38.20 \\
Pile Spacing 2D & 101.47 & 95.14 & 75.88 & 77.63 & 86.50 & 90.05 \\
Pile Spacing 3D & 95.37 & 88.90 & 72.86 & 75.68 & 83.50 & 90.04 \\
Pile Spacing 4D & 90.78 & 84.67 & 70.41 & 74.08 & 80.70 & 90.03 \\
Pile Spacing 5D & 86.89 & 81.56 & 68.48 & 72.54 & 78.40 & 90.02 \\
\hline
\end{tabular}

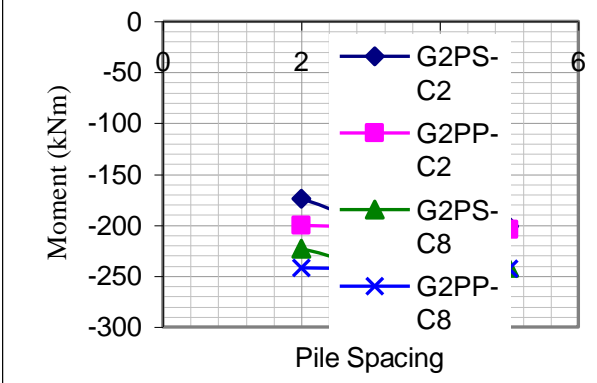

(a) Variation of moment at top of C-2 and C-8

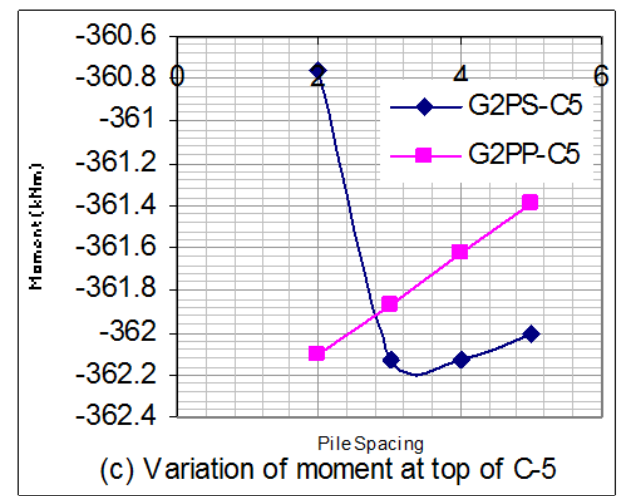

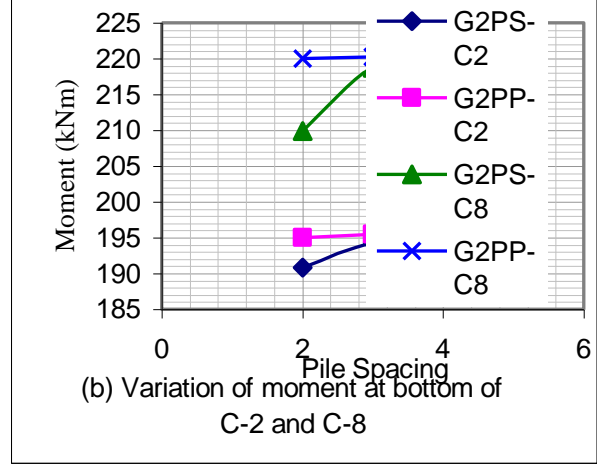

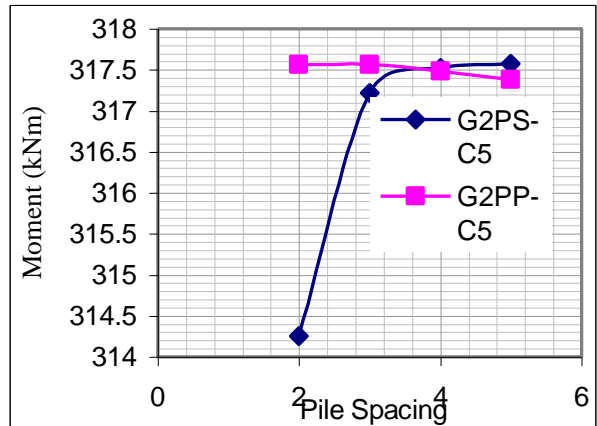

(d) Variation of moment at bottom of C-5

Fig. 4: Variation of moments with spacing in few typical columns (3-D FEA).

\subsection{Effect of SSI on displacement at top of frame}

From the results of parametric study conducted on a specific building frame supported on pile group comprising of two piles and having two different configurations, it is observed that displacement at top increases significantly when the soil-structure interaction effect is considered in the analysis. Effect of SSI is to increase the displacement in the range of $55 \%$ to $165 \%$ in the context of complete 3-D FEA and $42 \%$ to $103 \%$ when compared with the displacement obtained in view of fixed base condition.

Further, it is seen from the results of either analysis that displacement is more when the spacing between two piles is kept 2D and thereafter, decreases for higher spacing, i.e., 3D, 4D and 5D in 
both the configurations considered in the present study in either analysis. The general trend of reduction in displacement with the increase in spacing could be attributed to the overlapping of the stressed zones of individual piles at closer spacing. When the piles are closer, combined action of pile and that of pile cap is more rigid; and moreover, in three dimensional formulation it reflects block action owing to which displacement is observed more at the spacing of $2 \mathrm{D}$ and thereafter, it goes on decreasing.
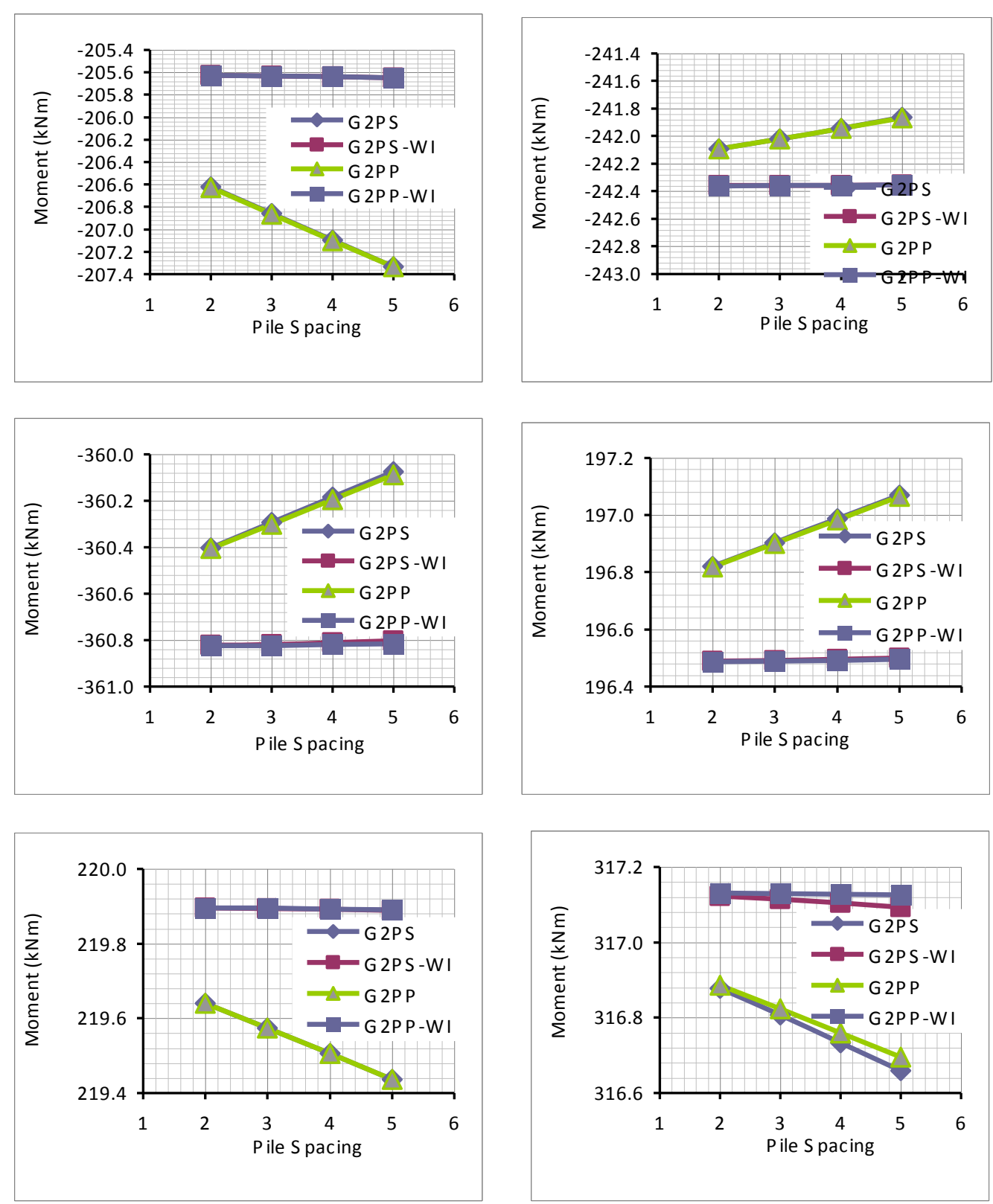

* WI indicates variation of moments obtained without considering interaction of cap and soil.

Fig. 5: Variation of moments with spacing in few typical columns (Simplified FEA). 
Effect of configuration of pile group particularly in the context of lateral load acting on the structure is quite significant on the response of the superstructure. From the results of 3-D FEA, it is seen that for the pile group with series arrangement displacements obtained are on higher side as compared to those obtained for the parallel arrangement of the piles in a group. For the pile group considered in the present study, parallel arrangement offers stiffer behaviour than series arrangement. Piles when laid in parallel arrangement offer more resistance as compared to the piles in series arrangement. This can be attributed to the larger area available for development of passive resistance.

When simplified modeling is resorted to, displacements obtained for the pile group with parallel arrangement of piles therein are found to be on the higher side as compared to the displacements obtained in view of series arrangement of piles in the group. From this it is seen that the series arrangement offers stiffer behaviour than the parallel arrangement. This could be because of the combined structural stiffness of pile and pile cap in parallel arrangement being small as compared to that in series arrangement as a result of which series arrangement offers stiffer behaviour. In case of short to medium length pile, it is a governing factor and the piles considered in the present study fall under the category of short piles.

As discussed above in 3-D FEA displacements at top of the frame are on higher side for the series configuration of the pile group whereas in simplified FEA, exactly opposite trend is observed. In continuum approach, i.e., in 3-D FEA, more passive resistance is available (offered by soil) due to the larger area of soil and hence, soil stiffness is much more. When combined effect of pile and soil is considered, combined structural stiffness of parallel arrangement is more than series arrangement in continuum approach while in spring approach (simplified FEA) since soil is modeled as discrete independent springs which are independent of the area of soil zone, passive resistance offered by larger area of soil can not be modeled properly. Soil is offering nearly same stiffness in series and parallel arrangement. Hence, combined stiffness of soil and pile will be lesser in parallel arrangement owing to which displacements obtained using simplified approach are higher in parallel configuration as against the trend observed in the complete three dimensional modeling of the foundation component.

Simplified FEA is attempted by considering and without considering the interaction between the pile cap and soil underlying it. Effect of the interaction of pile cap and soil underlying it is also significant on the response of the frame. Incorporation of this aspect is found to reduce the displacement which could be attributed to the increased soil stiffness. When the interaction between cap and soil is not considered, displacements are observed on higher side. For the pile group with series arrangement the trend of displacement with spacing is similar to that observed in the analysis when interaction is considered. However, in respect of the pile group with parallel arrangement of piles therein, the displacement with spacing is almost constant. It could be attributed to the fact that in simplified modeling combined structural stiffness of pile and pile cap is small and exclusion of the aspect of the interaction between cap and underlying soil further renders the arrangement weak.

\subsection{Effect of SSI on B.M. in superstructure columns}

Effect of SSI on B.M. in Superstructure Columns is found to be significant when the values of B.M. are obtained on the premise of fixed base approach. Effect on the columns placed on left hand side is minimum while that on right hand side, maximum.

The effect of SSI is found to increase the maximum positive moment in column by $14.01 \%$ and maximum negative moment by $27.77 \%$ in the context of 3 -D FEA. The corresponding increase in respect of simplified FEA is found to be $15 \%$ and $27.20 \%$ as compared with the absolute maximum values of the moments calculated on the premise of fixed base when the interaction between pile cap and underlying soil is considered. However, when this aspect is not considered 
in the analysis as is done in the simplified FEA, the corresponding increase is observed to be $27.31 \%$ and $15.05 \%$.

\subsubsection{Effect of configuration on variation of moment in columns with spacing}

Effect of configuration is found to be significant on the variation of B.M. in columns with spacing. The general trend observed pertaining to the variation of B.M. in columns irrespective of the configuration of the pile group is that in various columns (C-1, C-2 and C-3) in the row on left hand side of the specific frame at top B.M. increases on negative side with spacing and that at bottom, increases on positive side. For the columns in the intermediate row $(\mathrm{C}-4, \mathrm{C}-5$ and C-6) and that in the row on right hand side (C-7, C-8 and C-9) the trend of variation of B.M. is that at top of these columns, B.M. decreases on negative side with spacing and at bottom, decreases on positive side with spacing.

\section{3-D FEA:}

However, in 3-D analysis in respect of series configuration, at bottom of the corner columns (C1 and $\mathrm{C}-3$ ) placed in the leading row moment decreases up to a spacing of $4 \mathrm{D}$ and then slightly increases. For corner columns (C-4 and C-6) in the intermediate row, it is found to increase on negative side up to a spacing of $3 \mathrm{D}$ and then decreases on negative side for next higher spacing such as 4D and 5D. At bottom of these columns, it is found to increase on positive side up to a spacing of $3 \mathrm{D}$ and then decrease. At top of the central column (C-5) in this row, the moment is found to increase on negative side up to a spacing of $3 \mathrm{D}$, remain constant up to $4 \mathrm{D}$ and then decrease on negative side. In respect of pile group with parallel arrangement the trend of variation of moment with spacing is almost same as seen in the context of series configuration except that at bottom of C-5 where moment is observed to remain constant up to 4D and then, decrease on positive side.

\section{Simplified FEA:}

The trend of variation of moment at top and bottom of the various columns of the building frame is similar in respect of the series and parallel configuration. Moment at top of all the columns placed in the row on left hand side is found to increase on negative side with spacing and that at the bottom of these columns, increase on positive side for all the spacing considered in the study. For the columns in the interior row and that in the row on right hand side of the frame, moment at top is found to decrease on negative side for all spacing while that at bottom, decrease on positive side.

The general trend observed regarding B.M. in superstructure columns of specific building frame subjected to lateral loads apart from the usual loading with the pile foundation under consideration is that moment increases in leading row of the columns and decreases that in the rear row.

\subsubsection{Effect of interaction between cap and underlying soil on variation of moment}

When the values of moment obtained in view of the simplified FEA by considering and ignoring the interaction between the pile cap and soil underlying it are compared, trend observed regarding the increase or decrease in the moment at top and bottom of the columns placed in leading, intermediate and rear row almost remains same in respect of the series and parallel configuration, except that in case of corner columns in the rear row (C-7 and C-9) having pile foundation with series arrangement where moment increases for all the spacing unlike that observed in group of two piles having series arrangement. This may be because of the effect lack of precise interaction between two piles in a group. Moreover, it may be noted that the interaction between the cap and soil is neglected. Further, it is observed that the difference between the values of B.M. obtained corresponding to different spacing is very small as 
compared to that obtained with respect to the analysis carried out by considering this interaction aspect.

\section{CONCLUSIONS}

From the results discussed as above in view of the complete three dimensional finite element analysis and the simplified finite element analysis of the specific building frame considered in the present investigation in order to examine the effect of soil structure interaction, of the following broad conclusions can be arrived upon:

1. The effect of soil-structure interaction is to increase the top displacement in the range of $42 \%$ to $165 \%$.

2. With increase in pile spacing displacement at the top of the frame is found to decrease for the either configuration considered in the study in respect of either analysis; though decrease is marginal in respect of the parallel arrangement when the effect of interaction between the cap and soil is not considered.

3. Difference between the displacements is found to reduce with the increase in spacing.

4. Effect of the configuration of pile group with respect to the direction of the loading on the structure is quite significant on the displacement. In three dimensional FEA parallel arrangement is found to offer stiffer behaviour and in simplified FEA series arrangement is observed to offer stiffer behaviour. Displacements are found to be on higher side for series arrangement in respect of 3-D FEA and for parallel arrangement in the context of simplified FEA.

5. Effect of the interaction of pile cap and soil underlying it is significant; and displacements are found less when this interaction is incorporated in the analysis.

6. The effect of soil-structure interaction is to increase the maximum positive and negative moment in columns in the range of $14.01 \%$ to $15.05 \%$ and $27.20 \%$ to $27.77 \%$.

7. Effect of soil-structure interaction on moments in superstructure columns is also found to be significant. The effect is more on the columns on the right hand side. The effect on the columns on the left hand side is minimum and that on right hand side, maximum.

8. Effect of spacing on variation of moment is found to be significant though marginal and its trend remain almost stable for both the configurations of the pile groups.

9. The trend of variation in moments in superstructure columns for the either configuration of the pile group when obtained in the context of 3-D FEA is almost same with few exceptions. However, the trend is not found stable unlike that in case of simplified FEA and moments are observed to assume the normal trend as seen in simplified analysis either at the spacing of $3 \mathrm{D}$ or $4 \mathrm{D}$.

10. Effect of interaction between the pile cap and underlying soil is significant though marginal.

\section{SUMMARY}

The specific building problem considered in this paper is supported on the group of two piles with two different arrangements of piles therein. The frame is also subjected to lateral loads as shown in Fig.1. The effect of various parameters of the pile foundation is examined on the response of the building frame. The independent analysis of the frame is attempted on the premise of fixed column bases. The basic problem of the substructure considered here, i.e., pile group subjected to lateral load, is three dimensional in nature. Complete 3-D analysis requires 
more time and memory. The present paper deals with the analysis of the pile group using complete three dimensional finite element analysis and then, simplified approach whereby complete 3-D system is replaced by equivalent idealizations for various components. The finite element formulation adopted in the simplified analysis is not capable of considering torsional degree of freedom precisely. The Winkler's model ignores the continuous nature of soil. In simplified analysis, soil-pile system is analyzed on Winkler's hypothesis in which pile is treated as beam on elastic foundation according to which pile is assumed to be supported by a series of infinitely closely spaced independent and linearly elastic springs simulating soil. Hence, interaction between two piles through adjacent soil can not be accounted for as in a complete 3$\mathrm{D}$ analysis where proper interaction between piles in a group resting in soil continuum. Moreover, the Winkler's model that is employed in the simplified analysis suffers from few fundamental drawbacks such as interaction between adjacent springs is ignored even though there is very definite load spreading by vertical shear within an actual soil mass and next, compatibility between deformation of the foundation structure and founding stratum is ignored. Further, the methodology of simplified analysis as suggested by Desai et al ${ }^{14}$ considers fairly thin pile cap as against $500 \mathrm{~mm}$ thick pile cap. Notwithstanding, results yielded by the simplified finite element analysis agrees fairly with those obtained by complete 3-D analysis of the foundation system. It can be concluded that even though more complex problem of the interactive analysis of the building frame can be handled with significant accuracy within less time by resorting to the simplified approach, complete 3-D F.E.M. approach facilitates realistic modeling of all components of the foundation system gives accurate results.

All the same, it can be concluded that the effect of soil- structure interaction is observed to be quite significant when examined by complete 3-D analysis and simplified FEA for the type of foundation in view of the specific building frame considered in the present study.

\section{REFERENCES}

1. Morris, D. (1966), Interaction of Continuous Frames and Soil Media, Journal of Structural Engineering Division, ASCE, Vol. 5, pp. 13-43.

2. Lee, I.K. and Harrison, H.B. (1970), Structures and Foundation Interaction Theory, Proc. ASCE, 96, ST 2, pp. 177-198.

3. Lee, I.K. and Brown, P.T. (1972), Structures and Foundation Interaction Analysis, Journal of Structural Engineering Division, ASCE, Vol. 11, pp. 2413-2431.

4. King, G.J.W. and Chandrasekaran, V.S. (1974), Interactive Analysis of a Rafted Multistoreyed Space Frame Resting on an Inhomogeneous Clay Stratum, Proc. Int. Conf. on FEM, Australia, pp. 493-509.

5. Subba Rao, K.S., Sharda Bai, H., and Raghunatham, B.V. (1985), "Interaction Analysis of Frames with Beam Footings”, Proc. Indian Geotechnical Conference, Roorkee (India), Vol. I, pp. 389-395.

6. Deshmukh, A.M. and Karmarkar, S.R. (1991), "Interaction of Plane Frames with Soil", Proc. Indian Geotechnical Conference, Surat, Vol. I, pp. 323-326.

7. Mandal, A., Moitra, D., and Dutta, S.C. (1998), Soil- Structure Interaction on Building Frame: A Small Scale Model Study, International Journal of Structures, Roorkee (India), Vol. 18, No. 2, pp. 92-108.

8. Dasgupta, S., Dutta, S.C., and Bhattacharya, G. (1999), Effect of Soil- Structure Interaction on Building Frames on Isolated Footings, Journal of Structural Engineering, S.E.R.C. Chennai (India), Vol. 26, No. 2, pp. 129-134. 
9. Poulos, H.G. (1968), Analysis of settlement of Pile, Geotechnique, Vol. 18, No. 4, pp. 449471.

10. Coyle, H.M. and Reese, L.C. (1966), Load Transfer for Axially Loaded Pile in Clay, Proc. ASCE, 92, SM 2, pp. 1-26.

11. Poulos, H.G. (1971), Behaviour of Laterally Loaded Piles: II- Group of Piles", Journal of Soil Mechanics Foundation Engineering Division, ACSE, Vol. 97, No. 5, pp. 711-731.

12. Matlock, H. and Reese, L.C., Foundation Analysis of Offshore Pile Supported Structures, Proc. Of 5th Int. Conf. On Soil Mechanics and Foundation Engineering, Paris, pp. 91-97.

13. Desai, C.S. and Appel, G.C. (1976), 3-D Analysis of Laterally Loaded Structures, Proc. 2nd Int. Conf. On Numerical Methods in Geomechanics, Blacksburg, Vol. I, pp. 405-418.

14. Desai, C.S., Kuppuswamy, T., and Alameddine, A.R. (1981), Pile Cap- Pile Group- Soil Interaction", Journal of Structural Engineering Division, ASCE, Vol. 107, No. ST 5, pp. 817-834.

15. Chore, H.S. and Sawant, V.A., Finite Element Analysis of Laterally Loaded Pile Group, Proc. Indian Geotechnical Conference (IGC-2001), Allahabad, pp. 545-548.

16. Buragohain, D.N., Raghavan, N., and Chandrasekaran, V.S. (1981), Interaction of Frames with Pile Foundation, Proc. International Symposium on Soil- Structure Interaction, Roorkee (India), pp. 109-115. 